\title{
From the Indicators of General Comment No. 7 to GlobalChild
}

\section{A Decade of Work to Enhance State Parties' Accountability to Children}

\author{
Ziba Vaghri \\ School of Public Health and Social Policy, University of Victoria, Victoria, \\ British Columbia, Canada \\ zibav@uvic.ca \\ Lothar Krappmann \\ Max Planck Institute for Human Development, Berlin, Germany \\ krappmann@mpib-berlin.mpg.de \\ Jaap Doek \\ Vrije Universiteit, Amsterdam, The Netherlands \\ jaap@jaapedoek.nl
}

\begin{abstract}
Implementation of the United Nations Convention on the Rights of the Child (CRC) hinges on appropriate data collection to clarify actors' accountability and the impact of this on children. In spite of widespread ratification and revised legislation, most State Parties have not adequately implemented the CRC. The evidence demonstrates that indicators can assist with implementing and monitoring human rights. We present an account of a decade of work conducted under the auspices of the UN Committee on the Rights of the Child, towards developing indicator sets which map the degree of rights implementation. The work started with the rights of young children, outlined in the Committee's General Comment No. 7. It will culminate in a comprehensive monitoring platform, called GlobalChild, to improve State Parties' accountability to children through pointing at crucial aspects of the process of compliance with the CRC for which the State Party and its administration are accountable.
\end{abstract}




\section{Keywords}

accountability - Convention on the Rights of the Child - General Comment No. 7 indicators framework - monitoring - the Early Childhood Rights Indicators GlobalChild

Although all UN member states, except the USA, have ratified the UN Convention on the Rights of the Child (CRC) (OHCHR, 1989), implementation of the articles of the CRC proceeds hesitantly. This widespread observation invites the pivotal question: which factors hinder more progress and who is responsible to remove obstacles? Thus, accountability has become a subject of much discussion (Arts and Popovski, 2006; Newell and Wheeler, 2006; Lukas, Linder, Kutrzeba and Sprenger, 2016; Vandenbogaerde, 2016). Additionally, during recent years, the United Nations' Office of the High Commissioner for Human Rights (OHCHR) has urgently called for more attention to accountability issues (OHCHR, 2013).

The widespread ratification of the CRC promotes accountability to the wellbeing of children around the world. While some believe that the CRC itself can serve as an important tool for the promotion of the well-being of children (Doek, 2014; Bradshaw, 2014), literature presents a tension between children's rights and child well-being. Sandin (2014) describes child well-being as a longer-term historical concept that is highly dependent on culture and other contextual factors, and is therefore subjective, whereas the concept of child rights is newer and understood as a particular period of development during which children should have certain rights in order to ensure optimal development. Well-being is at the core of the CRC (Ben-Arieh et al., 2014), and can be seen throughout in its provisions for health care, education, social services and protection. Children's well-being urges the promotion of their rights, and implementing these rights enhances well-being (Casas et al., 2018). As one of the four guiding principles, the $\mathrm{CRC}$ recognises children's rights to express their views on all matters concerning them, which is related to high subjective well-being (Casas et al., 2018; Doek, 2014). The CRC accomplishes the promise of child well-being in several ways. It does so through the empowerment of children by declaring their right to be heard (Article 12). Additionally, the CRC attempts to provide conditions and environments conducive to children's well-being and development, for example through support for parents and family (through articles under the cluster of "family and alternative care"); through inclusion of social and cultural rights (through articles under the cluster of "civil rights and freedoms"); and finally through the right to various protections and provisions 
(through articles under the clusters of "protection from violence", "special measures of protection", "health and disability", and "education") for all children with a special focus on cases where the child's well-being is at risk (Doek, 2014).

Accountability is integral for good governance, and monitoring practices are essential to accountability. Embedded at the heart of monitoring is the notion that to manage the pathway to achieving socially desirable change, one must articulate targets consistent with that change, mobilise the necessary means, and employ policy instruments and mechanisms that translate those means into desired outcomes. New and revised legislation, domesticating the requirements of human rights treaties, in conjunction with appropriate monitoring mechanisms, imposes pressure upon governments to be accountable to the people in their jurisdictions.

Proper data collection is central to effective monitoring, and effective monitoring is important not only to measure the progress made but also the shortcomings in the implementation of human rights treaties such as the CRC. Successful data collection, in general, must begin with a clear understanding of what to collect in order to be able adequately to respond to a question. This is particularly important in relation to data collection with the intent of verifying human rights status. Verification of the status of many rights (either their fulfilment or violation), is only feasible through collecting data on attributes or elements of a right, which are closely related to its provision. This data can serve as indicators of the implementation of the right. For example, an adequate number of measures that serve to fulfil certain rights could be an indicator set for assessing the fulfilment of that right, e.g. assessing the right to pre-school education by the number of preschool centres per 500 households, the number of post-secondary institutions for training qualified pre-school teachers or the adoption of universal free of charge pre-school education policy. Researchers study which indicators best reflect the extent and the quality of a right and thus provide a pathway to change. Indeed, indicators can facilitate monitoring and promote compliance.

Since the early 2oth century, indicators have been used to operationalise complex policies, guidelines and resource documents in many different fields. The use of indicators in the human rights field began in the 1990s, and the development of child well-being indicators began in the 196os (Ben-Arieh et al., 2014). Currently, large numbers of indicators are available for monitoring child health, development and rights (Merry, 2011). Existing child rights indicators, however, do not address many aspects of a given right, which are relevant for its implementation, and/or address each right separately. More importantly, many do not link the state of different rights to children's health and developmental outcomes. The indivisibility and interconnectedness of human rights 
necessitates a coordinated approach, and the clarification of linkages between the indicators of rights to life and survival, protection, provision of services and participation is needed. Indeed, because the challenge of meeting the rights claims entailed by the CRC requires political action that cannot be taken in abstraction from economic, social and other considerations, it is essential that a system of organising data through indicator sets in this case generate relevant and coherent information for political deliberation.

In recent years, efforts to develop indicators as tools to monitor progress in the implementation of human rights have increased. Many organisations and child rights institutions (some of them mentioned in this paper), which are strongly involved in implementation efforts, have constructed various indicators more or less closely related to rights under human rights treaties. Eventually the онсHR, which has the mandate of supporting treaty bodies with the implementation of their respective human rights treaties, decided to demonstrate by illustrative indicator sets, in which way indicators can be instrumental to this end. It recommended that such indicators focus on two central questions: 1) Are governments, as primary duty bearers, upholding their obligations under their ratified human rights treaties; and 2) Are children, as rights holders, enjoying the fulfilment of their rights? Addressing the first question requires indicators verifying structures and processes in support of various rights, while responding to the second question requires indicators of outcomes (Vaghri et al., 2012).

This pattern of creating indicators under the three main categories of structure, process and outcome has become known as the sPo pattern and has gained increasing acceptance amongst child rights activists inspired by the seminal work prepared by a study group in the OHCHR (2012). One example of an effort to develop an SPO indicator system to enhance monitoring practices is a decade of work undertaken with regard to children's rights in early childhood, resulting in the development of the Early Childhood Rights Indicators (ECRI, 2012a, 2012b), based on the specifications of these rights in General Comment No. 7 of the UN Committee on the Right of the Child (hereafter: CRC Committee or Committee).

\section{Using sPo Model in Rights-Based Indicators}

Providing a complete overview of indicator studies is not an achievable goal, even if the focus is on studies which use the spo model. This model does not define an optimal state, rather it helps to identify chains of possible influences 
among factors on the three levels of structure, process and outcome. ${ }^{1}$ For this reason it has garnered much attention and approval in many fields.

Following the key features of this model, the European Union Agency for Fundamental Rights (FRA, 2010) initiative follows the SPO model for the construction of child-rights indicators. The initiative is based on the assumption that 'not all laws and policies of European Union (EU) necessarily benefit children' and there is a need for a holistic evaluation of the commitment, efforts of States and their outcome on children (FRA, 2010:14). Primarily relevant to CRC reporting clusters five, six, seven and eight, the FRA indicator set follows the tripartite model in order to 'transition away from indicators focused purely on outcomes - a particular feature of child well-being indicators - towards indicators which "better reflect the action and impact of policies"' (FRA, 2010: 22). Child well-being and child rights have a strong link between them; however, they have distinct features. Such distinction constitutes the basis of the FRA indicator set where the authors accept that while child well-being indicators reveal the state of children's lives, child rights indicators take into account contextual information, i.e. 'interaction between children, the state and society on matters concerning children' (FRA, 2010: 14). Similarly, Lundy (2014: 84) indicates that child rights indicators 'should not focus solely on the well-being of the child (as the rights holder) but must also measure the actions of the state (as duty bearer)'. Subsequently, measuring the actions of the state brings us inevitably to the use of structure- and process-related indicators.

The SPO model has also encouraged work in different world regions. Although not explicitly indicating an SPO structure, a South African approach to rights-based, child well-being indicators includes process, structure and outcome indicators. The implicit use of spo structure seems to be deriving from placing a rights-based approach in the centre of monitoring of child wellbeing. The authors cite Bentley (2003) who also lays down the three stages of measurement of rights-based monitoring (specification of what the State has to deliver, provisions for delivery, outcomes) (Dawes et al., 2007). These three stages refer to structural, process and outcome indicators, and demonstrate that rights-based monitoring and SPO model are in close connection. Accordingly, the monitoring framework captures the obligations of duty bearers by measuring three factors: critical child outcomes, specific constitutional and other statuary and regulatory provisions, and children's access to services and the quality of such services. (Dawes et al., 2007).

1 It was originally developed for the examination of health and care services in the 1960 s (Donabedian, 1988). 
UnICEF Child Protection Governance Indicators for East Asia and the Pacific, on the other hand, deliberately focuses on the processes relevant to child protection, and not on the actual outcomes such as prevalence rates of maltreatment. Accordingly, the authors accept that this Indicator Framework for Child Protection, 'is only one integral part of the overall assessment of child protection systems, which is complementary to, rather than an alternative of, an analysis of outcomes and results for children' (UNICEF 2012: 15). Such Framework provides valuable examples of process indicators. However, using only this indicator set does not provide enough information correctly to assess the full chain of steps in the realisation of relevant child rights.

The Child Friendliness Index, developed by the African Child Policy Forum, that builds on a rights-based approach, follows a tripartite system of legal and policy framework, resource commitment and child related service/ outcomes (Bequele, 2010). The structure is similar to the SPO model used by the OHCHR. However, some of the indicators that were classified as service/ outcome indicators bare the characteristics of process indicators. Nevertheless, the authors, while emphasising a rights-based approach, admit that using this three-dimensional approach assists them '[to put] in place appropriate legal and policy framework to protect children against harm and exploitation [and] in terms of budgetary allocation and achievement of outcomes for children' (Mekonen, 2009).

Another interesting example which shows the usefulness of the three-level spo model is the Juvenile Justice Indicators of the United Nations Office on Drugs and Crime (UNODC), which focus on the laws and policies in a given country. The indicator set is divided into two groups: quantitative indicators and policy indicators (UNICEF, 2006). Composed of 15 indicators, the indicator set does not address all of the potential child rights violations in these institutions making up the juvenile justice system. Indeed, the indicator manual indicates that the indicators are not designed to provide comprehensive information on all possible aspects of children in conflict with the law in a given country. Instead they represent a basic dataset and comparative tool to serve as a starting point for the assessment, evaluation and service and policy development. Although the manual does not explicitly indicate the utilisation of outcome indicators, the 11 quantitative indicators can be classified as, and demonstrate the characteristics of, outcome and process indicators. The Manual does not denote any intention for utilising SPO structure.

A meaningful use of SPO structure goes beyond just listing a number of structure, process and outcome indicators. It would require a methodological link - a correlational link between them. If we continue with the example of UNODC indicators, we observe no strong links between the indicators. 
Subsequently it becomes difficult to measure the impact and effectiveness of a policy indicator. For example, in the case of the "Complaints mechanisms", the indicator set does not contain any relevant outcome or process indicators and it is thus not feasible to assess the impact of such structure on children and their right to protection within the juvenile justice system. The situation is similar with the Defence for Children International's indicator set, "Violence against Children in Conflict with the Law”; Better Care Network and UNICEF's "Indicators for Children in Formal Care"; and UNICEF's "Manual for the Measurement of Indicators of Violence Against Children".

Indicator sets that do not follow an SPO structure have different aims compared to the international initiatives that are strictly in compliance with the spo model. For example, while the Child Protection Governance Indicators for East Asia and Pacific falls short in terms of having outcome indicators, it contributes greatly in monitoring structure and process variables related to the child protection system in a country. Indeed, if the goal is to have a complete picture, the tripartite model would allow one to see beyond state efforts which sometimes remain as examples of tokenism.

The literature warns about the risk of tokenism as a "tendency of a "means" to reach a goal becoming more important than the goal itself' (Op de Beeck, 2015: 251). For example, while measuring gender equality in education, enrolment rates disaggregated according to gender would not accurately reflect the fulfilment of the substantive rights. Contextual information through other indicators would be needed (Rosga and Satterthwaite, 2009). The school environment, curricula and methods of teaching should be in a way to enable girls and boys to participate in learning as equals. Therefore, gender equality would need to be integrated into the school curriculum and ways of teaching (Aikman and Unterhalter, 2007). This reveals the need to use qualitative indicators such as whether gender equality is included in the school curricula or whether there are policies for quotas in favour of girl children in schools, or whether teachers receive any relevant trainings.

A comprehensive review of existing indicators related to any article or General Comment of the CRC created between 2006 and 2016 (Vaghri and Erdemli, 2019) indicates that several indicators exist, covering many articles of the CRC under the reporting clusters, ${ }^{2}$ created by international agencies including Save the Children, the European Agency for Fundamental Rights, World Vision and

2 The reporting guidelines for State Parties' reports to the Committee list eleven clusters. In addition to the nine clusters related to the substantive articles of the CRC, the last two of these relate to the two Optional Protocols: the Optional Protocol on the Involvement of Children in Armed Conflict (OPAC) and the Optional Protocol on the Sale of Children, Child Prostitution 
UNICEF, among others. However, none of these efforts have followed the SPO pattern in full. Many of these indicator sets include indicators to monitor policies and/or processes, while many more have aimed to create indicators to monitor the impact and outcome at the child level (the indicators/targets of the SDGs are a distinct example). To the best of our knowledge, the indicators based on General Comment No. 7, today known as the Early Childhood Rights Indicators (ECRI, 2012a, 2012b), are the only child rights monitoring instrument that has fully complied with the SPO pattern. Indicator sets were created for each right, comprised of indicators of structure, indicators of processes, and indicators of outcome.

The use of indicators in this manner is valuable as it provides not just a single snapshot of a situation (e.g. poverty rate, extent of child labour, or enrolment in school), but elucidates the interplay of factors (i.e. structure and process-related factors) that contribute to the actual situation (i.e. outcome at the level of the right fulfilment and/or children's lives). Therefore, it is not merely constructing indicators, but coherent indicator sets (always within the frame of the structure/process/outcome), that can provide a comprehensive portrait of the state of any right. Such indicator sets will assist in analysing and understanding in which way the state and its actors are meeting their obligations under the CRC, in which directions the changes are occurring, who is accountable for such outcomes, and what are the changes in the lives of the children. This is a different approach than the collection of a number of indicators, which may be instructive, but do not refer to the implementation process in its entirety.

Indicator sets which follow the SPO pattern reflect essential requirements of the human rights mission: they correspond to the progressive implementation as they encompass many of the pre-requisites, conditions and mediating factors which make up the implementation process. It is culturally sensitive as it has to be adapted to the contexts in which it is used (to the domestic and local legislation; to policies, institutions and measures; to family structures and local customs). It meets the indivisibility of human rights as it searches for mutual influences across and within the three levels of the SPO indicator model. It is particularly meaningful when repeatedly used as the changes observed can give hints at the crucial junctions which hinder or promote implementation.

Thus, one may wonder why has this indicator system not been used sooner by human rights institutions and activists for analysing and monitoring

and Child Pornography (OPSC), which are to be reported on by State Parties initially upon ratification as separate reports, and subsequently included with each periodic report. 
implementation processes, as this sPo model is broadly and successfully used in the field of health services and care (e.g. Gardener et al., 2013; Carayon et al. 2014). The literature in this field of research and also the OHCHR group (OHCHR, 2012) point at several cautions which should be observed. It is essential that the attributes of the rights under study are carefully defined, since an inconsistent SPO system will generate misleading results. The success of the SPO indicator system is also dependent on the availability as well as of the quality of data in the fields examined. Lastly, competent resource persons are needed to search for data while keeping in mind the potential bias in the collected information because of the affiliation of these persons to governmental or non-governmental agencies or organisations.

Only when these requirements are met, the spo model will generate valuable results. Researchers warn against misinterpreting correlations as causal relationships (Carayon et al., 2006). Only when data can be collected on a large scale, statistical analysis allows for impact assessments. Since some data included in our child-rights indicator system is provided on the nominal or ordinal level only, such analyses are not possible. Consequently, the spo-based indicator system is a heuristic which will become increasingly robust when data collection and analysis is repeated regularly and the effects of provisions and measure become measureable. The entailed costs may explain why such comprehensive indicator studies in the health care system prevail, where valid results are immediately instrumental to improve the balance of expenses and revenues. At long sight, sPo-based indicator studies and their insights may have to focus on a number of overriding ways of rights implementation and their improvement.

The indicators developed for ECRI (indicators of General Comment No. 7) as they stand today, is a distinct, and the very first, example of using an SPO pattern in its entirety. The outcome is a set of indicators that can serve to enhance governments' accountability, in particular, their commitments (structures) and efforts (processes), to young children by assisting the monitoring efforts of the CRC Committee. The following provides a chronological summary of a ten-year journey towards development of ECRI.

\section{The Journey of Early Childhood Development within Two UN Agencies}

The significance of the early years for the human life course started to gain recognition during the second half of the last century; it was well known that the early years of life are the foundation of all paths of development (Marope and 
Kaga, 2015). During the process of drafting the CRC, unfortunately, a UNESCO proposal to the working group asking to include an article on Early Childhood Care and Education was rejected by a majority of state delegates (OHCHR, 2007). The premise of such rejection was that the young belong to the family. So, by the early years of this century, the "world" was long waiting for an authoritative statement on early childhood care and education as the right of the child.

In the early 2000s, two parallel processes in separate UN agencies were foundational to the joining of the previously unconnected areas of early childhood development (ECD), social determinants of health (SDH), and human rights indicators, leading ultimately to the work on ECRI. While the World Health Organisation (WHO) began to acknowledge the significance of ECD as a potent SDH in achieving health equity, the OHCHR increasingly recognised the important role human rights indicators can play in measuring compliance with human rights treaties and improving outcomes.

\subsection{ECD and the WHO Commission on Social Determinants of Health}

In 2005, in response to the gross and unjust health inequity observed within and across nations, the World Health Organisation (wHO) set up the Commission on Social Determinants of Health. The task of the Commission was a) to compile evidence to understand how health equity can be promoted through improvements in SDH and, b) to foster a global crusade to achieve it.

The Commission designated Knowledge Network Hubs around the globe to work on assigned determinants. The WHO recognised ECD as a potent SDH and designated the Human Early Learning Partnership (HELP) as the ECD Knowledge Network Hub (ECD-KN). In this role, HELP conducted two years of intensive research to synthesise knowledge about opportunities to improve the state of ECD and, as a result, the state of health and health equity in populations.

At the end of this period, the ECD-KN created a comprehensive report and submitted it to the wHO Commissioner (Irwin et al., 2007). The report synthesised knowledge about opportunities to improve the state of ECD on a global scale and confirmed a strong association between child survival and child development, and that child survival and health agendas are indivisible from ECD. It, therefore, asserted that our developmental approach to the early years should include the factors that affect child health and survival, but go beyond these to consider how the early years can be used to create thriving global citizens. It also provided a framework for understanding the environments, and their characteristics, that play a significant role in influencing early development. 
The principle strategic insight of the report was that the nurturant qualities of the environments where children grow up, live and learn - parents, caregivers, family and community - will have the most significant impact on their development. However, the document went further by addressing the situations when parents, and caregivers cannot provide strong nurturant environments without help from local, regional, national governments and international agencies. Lastly, it examined some of the best practices in terms of policies and processes conducive to better developmental outcomes during the early years.

The report made several recommendations to improve ECD, including the necessity for the formation of global alliances to work on ECD-related issues (i.e. promotion of breastfeeding, play, quality early learning programmes, etc.) and their monitoring processes that are built with the purpose of enhancing the developmental outcomes of the early years. It highlighted the significance of monitoring ECD-related processes in improving developmental outcomes for young children and also in achieving a better and more equitable state of population health. Additionally, the Final Report of the wHo Commission on SDH asserted that such populations with more equitable health would enjoy a more prosperous economy and sustainable development (CSDH, 2008).

Given its central message about the crucial significance of young children's environments for their best possible development, the ECD-KN presented the Total Environment Assessment Model for ECD (TEAM-ECD) as a framework for enhancing the developmental outcomes of the early years within the final report to the WHO Commission (Irwin et al., 2007). The TEAM-ECD framework is grounded in Bronfenbrenner's (1979) socio-ecological model of human development with a focus on the early stages of this developmental pathway. TEAMECD basically depicts that ECD is a bio-social process and the net result of the constant interplay between the biology of children and the quality of their experiences within layers of environments that surrounds them (Figure 1).

It provides a framework for understanding the environments (and their characteristics) that play a significant role in providing nurturant conditions to children and was meant to serve as a guide to understanding the relationships between these environments, putting the child at the centre of the framework. The environments are not strictly hierarchical; however, they are truly interconnected. The most proximal environment of the child is the family environment. At a broader level are residential communities (such as neighbourhoods), relational communities (such as those based on religious or other social bonds), and the ECD service environment. Each of these environments is situated in a broad socio-economic context that is shaped by factors at the regional, national and global level. 


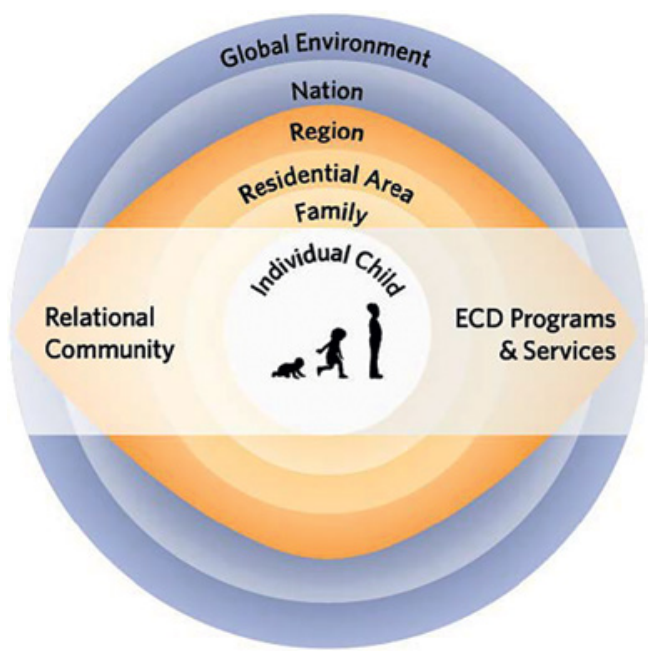

FIGURE 1 TEAM-ECD framework (Irwin et al., 2007)

The concluding message of the report was that socio-economic inequities in developmental outcomes of the early years originate from inequities in the experiences and environmental conditions of children. A broad array of experiences and environmental conditions matter, from those intimately connected to the child (for example, the quality of time and care provided by parents/ guardians and the physical conditions of the house), to the distal factors that in various ways influence the child's access to nurturant conditions (such as government policies that provide families and communities with sufficient income, employment and unemployment insurance, health care resources, early childhood education and safe neighbourhoods, among others). Lastly, the report also pointed out the significance of monitoring the global systems, such as the CRC, that are in place to safeguard the development of children, particularly during the early years (Irwin et al., 2007).

\subsection{Indicators and the $\mathrm{OHCHR}$}

In 2006, while the WHO's global crusade of the Commission on Social Determinants of Health (CSDH) moved ahead at full speed, chairpersons of all human rights treaty bodies at that time recommended the OHCHR construct a system of indicators that represent the scale of human rights implementation in the State Parties. The human rights committees were dissatisfied with the statistical information contained in most of the State Party reports. Significant data was completely missing or fragmentary, the base of the data 
collection was unclear, or presented data was not comparable across sections of the report or years of reporting. Committees expected that a standardised set of relevant indicators would strengthen the monitoring procedures of all committees.

An OHCHR team studied existing indicators for human rights implementation and made proposals to develop and use indicators based on the human rights obligations of State Parties (Malhotra and Fasel, 2005). The онснR team focused on rights enshrined in the International Covenant on Economic, Social and Cultural Rights (ICESCR), as this treaty is a base for subsequent treaties specifying rights of the Covenant for groups of persons or particular situations in which rights implementation may be challenged. The OHCHR team articulated 16 indicators, including seven indicators related to child rights (i.e. national policy on sexual and reproductive health, the right to education in national law, compulsory and free primary education, births attended by skilled health personnel, public nutrition programmes, ratio of pupils to teaching staff, infant mortality rate - see OHCHR, 2012). While extensive, these indicators did not address child rights comprehensively, were not directly linked to the CRC monitoring efforts and thus needed more adaptation to the analyses and the directions outlined in its General Comments.

Overall, the work of the ОНСнR (2012) underlined the usefulness of a comprehensive data collection and indicator framework responding to the three overarching categories of questions:

1) Structure-related indicators: questions to verify commitments made by governments in support of different rights (e.g. policies, laws, and financial provisions);

2) Process-related indicators: questions about the actions taken on those policies (e.g. through programmes, initiatives and allocation of responsibilities); and

3) Outcome-related indicators: questions to verify the impact of these commitments and actions on the environment of a given right (e.g. increased school enrolment as a proxy indicator of progress in the enjoyment of the right to education) or, better yet, on the quality of children's health and development (e.g. increase in developmental scores of children as measured by widely recognised standardized tests).

These SPO categories are also referred to as commitment, effort and outcome indicators, respectively. The original concept was that aspects of the implementation of a right should be addressed on all three levels as implementation 
proceeds from legislation and other manifestations of commitment to activities which result in the effective practice and enjoyment of a right. However, ultimately, the 16 indicators of the OHCHR refer to either the state's commitment, efforts or resulting outcome. Thus, for instance, the right to education indicator is conceived as a commitment indicator, the nutrition indicator as an effort indicator and child mortality as an outcome indicator. Although the CRC Committee welcomed the work of the OHCHR team, the restriction of indicators to one of the SPO levels limited the immediate usefulness of the work of the OHCHR group for the Committee and its monitoring efforts.

General Comment 7: Filling the Gap for ECD under the CRC

Aware of the importance of early childhood, the CRC Committee made an alarming observation that despite the clear definition of the "child" as "[...] every human being below the age of eighteen years [...]' i.e. including the first years of life (CRC, Art. 1), many State Parties were not reporting consistently and comprehensively on younger children (under eight years of age). Despite the Committee's many reminders, this issue persisted. In order to provide guidance and encourage more inclusive reporting, the Committee decided to organise a Day of General Discussion on early childhood and the rights of the child in 2004.

Based on the recommendation made during the Day of General Discussion, General Comment No. 7, "Implementing Child Rights in Early Childhood" $\left(\mathrm{GC}_{7}\right.$ ), was drafted and adopted by the Committee in 2006 (UNCRC, 2006a; UNCRC, 2006b). Highly welcomed by relevant UN agencies and international child rights organisations, $\mathrm{GC}_{7}$ generated increased attention to young children's rights worldwide. $\mathrm{GC}_{7}$ provided an authoritative reference for their activities by explaining which rights provided in the CRC are of particular relevance for young children, including the right to family, right to social security, right to freedom from violence, right to education and right to play and rest. This General Comment demanded a "positive agenda" for early years, an agenda that will be antideficit and take preventative measures to inhibit deficits from happening. $\mathrm{GC}_{7}$ also commandingly called for an agenda that will also strengthen the recognition of young children as rights holders and active participants in all actions concerning their lives and development.

While $\mathrm{GC}_{7}$ represents firm and clear guidance to duty-bearers in fulfilling their obligations to young children, it was soon discovered that the available data about young children was insufficient. Even UNICEF's well-known 
data-collection system, the Multiple Indicators Cluster Survey (MICs), at the time, lacked substantial data collection related to young children. ${ }^{3}$

Many UN agencies, including UNICEF, WHO and UNESCO, were among the agencies and organisations that commented on the draft of $\mathrm{GC}_{7}$. When $\mathrm{GC}_{7}$ was published, UNICEF, WHO and the Committee came together to plan a campaign to disseminate $\mathrm{GC}_{7}$. The wHO invited the CRC Committee to present $\mathrm{GC}_{7}$ in an event at its headquarters in Geneva. During this gathering the idea of constructing indicators for $\mathrm{GC}_{7}$ was created. Around the same time, UNICEF requested advice from the Committee on a revision of the MICS based on the Committee's analysis of State Party reports. Moreover, the intention to provide feedback to UNICEF on the MICS influenced the decision of the Committee with regard to the creation of indicators specified in $\mathrm{GC}_{7}$. A dissemination project of the $\mathrm{GC}_{7}$ in Jamaica, supported by the Bernard van Leer Foundation, produced additional evidence that a rights-based indicator system supporting the monitoring efforts of the CRC Committee was urgently needed.

In light of all this, Clyde Hertzman (ECD-KN), together with colleagues from who, UNICEF, Bernard van Leer Foundation and others, approached the Committee with a proposal to create, in close cooperation with the Committee, a set of indicators addressing the rights of young children as specified in $\mathrm{GC}_{7}$. The proposal was well received, and a team was assembled to undertake the work.

\section{4}

\section{$\mathrm{GC}_{7}$ and Development of the Indicators of $\mathrm{GC}_{7}$}

Led by Hertzman, this international team of experts from the fields of early childhood development, human rights and child advocacy was of the view that while $\mathrm{GC}_{7}$ is a comprehensive resource intended to facilitate more concise reporting and targeted monitoring, it remains underutilised. Highlighting the need to increase the utility of this General Comment, the group proposed to the CRC Committee the creation of an indicator set for the rights of young children as thoroughly explained in $\mathrm{GC}_{7}$ using the OHCHR (2012) SPO framework. A set of indicators would serve not only as a monitoring tool, but would also act as a catalyst for addressing the existing deficit in data on young children

3 The Multiple Indicator Cluster Surveys (MICS), developed by UNICEF, is an international household survey programme comprised of indicators related to several areas of human development including, health, water and sanitation, and child protection. 
by providing a framework for comprehensive data collection on the various aspects of young children's rights.

Jaap Doek, Chairperson of the Committee, invited the group to form an ad hoc team (hereafter known as the $\mathrm{GC}_{7}$ Indicators Group), and to begin work on developing a set of indicators for rights under the $\mathrm{CRC}$, re-articulated within the $\mathrm{GC}_{7}$ for young children. With the international programme of HELP acting as the secretariat of the $\mathrm{GC}_{7}$ Indicators Group, within two years (2006-2008) the $\mathrm{GC}_{7}$ indicator set was constructed.

In 2008, the $\mathrm{GC}_{7}$ Indicators Group presented the result of its work to the Committee. The Committee received the indicators of $\mathrm{GC}_{7}$ with keen interest, renewed its support, and encouraged the $\mathrm{GC}_{7}$ Indicators Group to pilot their work. The ECD cluster of UNICEF-HQ and HELP signed an agreement under which it was agreed that HELP would lead the development of a manual of the $\mathrm{GC}_{7}$ indicators in collaboration with the larger $\mathrm{GC}_{7}$ Indicators Group, funded by UNICEF. Under the renewed auspices of the Committee, a revised "Manual for Early Childhood Rights Indicators" was developed, which served as the resource document for the first pilot conducted in Tanzania. Subsequent to the pilot, an advanced Draft Manual was published (Vaghri et al., 2010).

This functional focus of the indicator sets on monitoring and implementation also contributes to settling another problem: the Committee observed that governments detest to be ranked on the basis of a single indicator or some incoherent indicators, usually outcome indicators, which often are interpreted as demonstration of global failure to implement the CRC. Governments insist that the background of their efforts, particular conditions, available resources as well as pertinent obstacles are considered in order to understand the situation of children and their rights in their countries. Indicator sets, which cover the sPo levels of promoting and aggravating factors, do not allow assigning a global score to a state for the purpose of comparison with "better" states. Instead these sets give a thorough diagnosis of the interplay of factors, and this way, fuel a targeted and effective monitoring process.

Building upon the work of the OHCHR, the $\mathrm{GC}_{7}$ Indicators Group followed the original concept that indicators of progressive implementation of a right should be a group of significant measures that cover all three sPo levels of implementation (e.g. the implementation of, for example, the child's right to education must be studied in view of commitment, efforts and outcomes). With this foundational framework, the intention is better to understand the stepwise implementation of a right: for example, from its incorporation into the legal system of the State Party via diverse provisions established to facilitate school attendance, to achievement, graduation and prevention of dropout. Such an indicator set gives information about aspects of rights implementation and 
puts it into context. It is designed as a monitoring instrument that relates commitment, efforts and outcomes to each other while showing deficits, obstacles and supporting conditions and factors in order to improve and direct the process of a complete implementation (Vaghri et al., 2010).

\section{Piloting the $\mathrm{GC}_{7}$ Indicators Globally}

The very first attempt to study the dissemination of the $\mathrm{GC}_{7}$ was carried out by the Bernard van Leer Foundation (BvL) in partnership with UNICEF in Jamaica in 2006. The work of BvL served to assess the reception and understanding of $\mathrm{GC}_{7}$ and the rights of young children in Jamaica, with a particular focus on raising awareness with stakeholders and developing an action plan for a positive agenda for children. A user-friendly guide of $\mathrm{GC}_{7}$ was developed and launched, the impact of which was monitored and evaluated (Bernard van Leer Foundation, 2007). This initial study of the dissemination process of $\mathrm{GC}_{7}$ provided valuable data to inform the subsequent pilots of the $\mathrm{GC}_{7}$ Indicators.

In 2008, when the first draft of the $\mathrm{GC}_{7}$ Indicators was presented to the Committee, Yanghee Lee, ${ }^{4}$ through a letter sent to the $\mathrm{GC}_{7}$ Indicators Group, advised the Group to pilot the indicators. Subsequently, the Group decided on three jurisdictions, representative of low (Tanzania, 2009-2010), middle (Chile, 2011-2012), and high (British Columbia, Canada, 2015-2017) resource settings, based on income per capita.

The first pilot, taking place in the Republic of Tanzania, demonstrated that the $\mathrm{GC}_{7}$ indicators could work as a method for national and intersectoral selfstudy to identify policies, programmes and outcomes conducted for the wellbeing and development of children in early childhood (Vaghri et al., 2011). It proved as a valuable tool to assess the degree to which the conditions conducive to fulfilling child rights were in place for young children. However, due to the scarcity of the supporting documents in response to the outcome questions, not many conclusions could be made about the impact of these capacities on the rights and lives of the children. The pilot also highlighted the lack of cooperation amongst governmental departments with regard to children's issues. Indeed, the minister of the focal ministry partnering with the $\mathrm{GC}_{7}$ Indicators Group during the pilot noted this with regret, and had the intention to improve coordination of child-related issues.

4 Yanghee Lee, a Korean developmental psychologist, served as chair of the UN Committee on the Rights of the Child (2007-2011), and has also served as chairperson of the Meeting of Chairpersons of Treaty Bodies (2010-2011). 
In preparation for the second pilot, to take place in the Republic of Chile, the $\mathrm{GC}_{7}$ indicators were digitised in 2010. The resultant digital tool was renamed the Early Childhood Rights Indicators (ECRI, 2012a, 2012b) and was comprised of 17 indicators sets (Appendix I) each one comprised of 3 sets of structure, process and outcome-related indicators (Appendix II, an excerpt from a sample indicator).

Within Chile, a qualitative study assessing the impact of the pilot through a series of semi-structured interviews with ECD-focused members of the government and government services highlighted several key impacts of the pilot. Working with the indicators brought ECD to the forefront of the attention of the government, and led to an improved understanding of $\mathrm{GC}_{7}$ and children's rights. Interviewees indicated that the pilot work led to a shift in discussion that was conducive to intersectoral collaboration, and also expressed that through the process of data collection they became aware that they had little information on some aspects of young children's rights and lives. Lastly, they discovered multifaceted problems and the insufficient provisions, and were more or less unable to give an adequate response to what was asked in the indicators. Thus, the data the pilot could collect was fragmentary, but this was an eye-opener for government and administration (Vaghri and Gibson, forthcoming).

Additionally, a policy brief published about the pilot served as a discussion paper at a gathering of paediatricians of Latin American countries in Cartagena, Colombia (Molina et al., 2012). Initiated by UNICEF country offices, Vaghri received several invitations to Latin American countries as ECD stakeholders became interested in this indicator tool and its way to analyse the interplay of factors influencing provisions and resources for thriving child development.

In 2015, with provincial funding secured from British Columbia's Island Health Authority, the final pilot of ECRI was conducted in the Province of British Columbia (BC) in Canada. The team is currently in the process of finalising the pilot report.

The pilots in three regions with different levels of development confirmed that the ECRI tool as it is today, comprised of 17 indicator sets following the generic SPO structure recommended by the OHCHR (2012), stood the test of reality of the field. The indicators had the ability to translate the CRC into real world changes for young children. The pilots also exposed the challenges as well as successes in piloting ECRI. The recurring themes of all three pilots were the potential of, and need for, such a tool, and its ability to lead not only to better monitoring, but also better cooperation within state institutions. The world is not yet at a stage where children's rights are guaranteed across the globe. Many countries do not take their responsibility and their accountability to young children genuinely, and fail to fulfil the commitments put upon them 
by the CRC. Therefore, availability of monitoring tools such as ECRI are crucial, as such a tool can assist in evaluating the progress made by the governments in upholding their obligations under the CRC. Additionally, tools that can help governments with conducting an inventory of their existing capacities and identifying gaps within these is equally important.

Existing evidence indicates that the most successful ECD initiatives and programmes are those that are intersectorally crosscutting. Both Tanzania (Vaghri et al., 2011) and Chile (Vaghri et al., 2013) pilots indicated that the pilot process initiated an intersectoral collaboration and opened the lines of communications between and within government institutions, that were underutilised despite their significance in furthering the overall goal of these organisations and improving the state of early child development. In May 2019, a few members of the $\mathrm{GC}_{7}$ indicators team will convene with the Bureau of the $\mathrm{CRC}$ to discuss the uptake of the tool by a larger number of the States Parties and how the tool can serve the mandate of the Committee and $\mathrm{GC}_{7}$.

\section{Reception of the $\mathrm{GC}_{7}$ Indicators Work and the Committee's Continued Efforts toward Accountability}

After finalising the manual of the $\mathrm{GC}_{7}$ indicators based on the pilot studies in Tanzania and Chile, and after a visit to the Chile pilot site by Committee chairperson at the time, Jean Zermatten, ${ }^{5}$ the $\mathrm{GC}_{7}$ Indicators Group recommended that the Committee's reporting guidelines point State Parties to the ECRI Manual (Vaghri et al., 2010), with advice to prepare their reports in the manner outlined in the Manual. The team also suggested that every General Comment of the Committee should include a section which explains the need for indicators that support the monitoring of the implementation of the right under consideration in the respective General Comment.

The Committee itself has no resources for the elaboration of such indicators. It approved, however, the request that not only this General Comment but all others should propose an appropriate data collection and indicator system. The Committee agreed and included a respective paragraph in the General Comment in progress at that time (UNCRC, 2011, para. 72).

In 2012, the Committee discussed such issues with child rights and indicator research experts from UN agencies, international NGOs and academia,

5 Honorable Jean Zermatten, a Swiss judge specialised in juvenile justice, served as chair of the UN Committee on the Rights of the Child (2009-2013) and currently serves as Steering Committee chair of GlobalChild, an initiative that will be described in upcoming sections of this paper. 
including a few members of the $\mathrm{GC}_{7}$ Indicators Group, in a conference in Sion, Switzerland, in order to establish closer cooperation among experts and organisations to clarify standards of implementation (i.e. what is adequate implementation) and to provide instruments that allow for analysis of efforts and progress made (i.e. in relation to structure, process, or outcome).

Attempts were made to establish an organisational structure to strengthen accountability within human rights implementation. A Global Reference Group on Accountability was formed, comprised of a number of knowledgeable and experienced child rights activists; this group promised strongly to support activities to strengthen accountability by employing an indicator system in an organised and systematic manner. The efforts were renewed at a follow-up meeting of the Committee in Annecy, France, in 2014. It became evident that such an endeavour requires the strong involvement of Committee members so that the indicator sets reflect the juridical interpretation of the CRC articles authorised by the Committee. It turned out to be very difficult to establish firmly such a widespread network of persons and institutions. Therefore, other methods had to be employed to build further on the positive results of the $\mathrm{GC}_{7}$ pilots.

From ECRI to GlobalChild: The Journey Continues

The exemplary model of the $\mathrm{GC}_{7}$ Indicators inspired the plan to develop indicator sets for all the articles of the CRC. Hertzman and Vaghri agreed on the design of the GlobalChild project, a project to develop indicator sets for the entire substantive rights under the CRC, during the last few months of Hertzman's life. Vaghri designed the full study of the GlobalChild, which would be a comprehensive child rights monitoring platform that would serve many purposes including facilitating report-writing, monitoring of the implementation of the CRC, and strengthening of both the treaty body as well as the State Parties' accountability. Vaghri secured two Canadian research grants to realise the intended project: one from the Michael Smith Foundation for Health Research in 2015 and one from the Canadian Institutes of Health Research in 2016.

As the illustrative indicators established by the OHCHR did not cover the whole range of child rights and all aspects of the implementation process, they cannot be a comprehensive base for the State's reporting and the Committee's monitoring. A comprehensive, integrated set of indicators tied directly to the CRC would be necessary to facilitate effective reporting, monitoring and implementation. 
GlobalChild is a $5^{+} 5$ years project. During the first five years, an indicator set will be developed, following the SPO pattern, for each substantive right of the CRC (Articles 1-42) articulated under nine of the established reporting clusters. ${ }^{6}$ These indicators will then be digitised to create an electronic child rights monitoring platform: the GlobalChild tool. With its initial phase facilitated by Canadian funding, GlobalChild will give particular attention to Canada's child rights issues, before expanding globally. GlobalChild will also be translated into French.

The GlobalChild team will then pilot the English and French versions in an Anglophone and Francophone region of Canada, respectively. The subsequent five years, upon securing funding from international agencies, will focus on piloting the GlobalChild tool globally and collaborating with the CRC Committee to ascertain the role it can play in State Parties, reporting to contribute to enhancing accountability to the children of their jurisdictions.

It is noteworthy to mention that although the first five years of the project is housed in and funded by Canada, GlobalChild is an international project by virtue of the very fact that it is operationalising an international human rights treaty, receives guidance from an international board of child rights experts, and is conducted in close collaboration with the CRC Committee. Its outcome will serve all 196 State Parties to the CRC.

The entire initiative of developing and monitoring the Early Childhood Rights Indicators expanded over a decade (2006-2017). Encouraged by this decade of experience with indicators and child rights monitoring tools, there is good reason to expect that GlobalChild will be useful for a range of different stakeholders. Besides the detailed instrument elucidating the implementation process article by article, GlobalChild will integrate child-related targets of the Sustainable Development Goals (SDG). In light of recent attention to the intersection of child rights and the SDGs, all child-focused indicators of the SDGs have been extracted and will be included within the indicator sets of GlobalChild. SDG-related questions will be tagged within the GlobalChild tool (for example, question 7, if it mirrors a child-focused SDG target, will appear as Q.7SDG, instead of appearing as Q.7). A feature will facilitate a click button to extract all SDG-tagged questions. This will enable GlobalChild to serve as a tool to track the child-focused indicators of SDGs as well.

6 Initially, GlobalChild will include the nine clusters relating to the substantive articles of the CRC. However, as the vast majority of State Parties have ratified the Optional Protocols, the GlobalChild team plans to secure funds to extend the tool to cover these last two clusters in order to reflect the full list of eleven clusters of the reporting guidelines. 
Overall, the outcome of our three ECRI pilots confirms that an indicators framework such as the one used in developing ECRI can serve effectively in creating tools to take inventory of the capacities of different State Parties to support children's rights. Such an inventory, in addition to serving as a grid for CRC report writing, can assist all levels of governments with preparing evidence-based action plans. It can reveal what is in place, what is missing, and it may even, through longitudinal data collection, help to some extent to understand the impact of states' existing capacities, provisions and measures on children. This information can serve a great purpose in the hands of politicians and policymakers.

Additionally, such a tool can assist non-governmental monitoring entities, such as children's ombudspersons and child and youth representatives, in preparing their annual reports to parliaments or legislative committees. Lastly, the periodic data collection by platforms such as GlobalChild will generate an instrumental data repository for different governments to track changes over time, and for academic and civil society to investigate a given research question or issue.

In view of the mentioned efforts already undertaken to establish indicators for measuring implementation of specific parts of the CRC (e.g. on health care, education, alternative care and on juvenile justice), GlobalChild attempts to work on a comprehensive set of indicators for all provisions of the CRC in order to avoid too much fragmentation. This will be achieved by close cooperation with a large number of Canadian and international child rights and child development agencies and entities. However, it is the intent to use previous work in building some parts of the GlobalChild tool.

Both tools mentioned in this document, ECRI and GlobalChild, are grounded in a rights-based approach to children's protection, health, development and participation, and therefore place emphasis on children as social actors with evolving capacities, and articulate children's rights to express their views and to be heard. This approach is not only about fulfilling a set of rights in a formal way but more importantly, it is about the non-discriminatory enjoyment of these rights by all children globally. In compliance with the principle of child participation, the GlobalChild team has recently launched Global Child Rights Dialogue (GCRD). ${ }^{7}$ GCRD is a child consultation process, through

7 Global Child Rights Dialogue (GCRD) webpage can be accessed at: https://onlineacademic community.uvic.ca/globalchild/global-child-rights-dialogue/. 
which the outcomes of the indicators development team are subjected to the opinions of children from 35 countries across the globe. GCRD completed in early 2019 .

\section{$8 \quad$ Closing Remarks}

There is now broad international recognition of the importance of indicators for measuring progress and shortcomings in all fields of human lives. The development and use of indicators as tools to measure progress becomes even more critical given the fact that the global community will soon embark on the grand task of measuring progress made to implement the SDGs. In the context of child rights, various efforts to develop indicators have been made. To our knowledge, the most comprehensive indicator system focusing on child rights at present is the ECRI, which has devoted specific attention to rights specifically relevant to young children. As all sets comprise indicators of structure, process and outcome, the tool is particularly instrumental for the monitoring of rights implementation (ECRI, 2012a, 2012b). This work and the results accomplished now serve to develop a comprehensive set of indicators to monitor the entire CRC, called GlobalChild.

The authors would like to emphasise that this indicator system is not constructed to replace existing indicators that measure the proportion of children who suffer violations or enjoy relevant aspects of their rights; these tools have their own value for bringing data to the attention of the public and politicians. Rather, it is our goal to ascertain that the spo pattern makes it easier to understand which factors on the structure or process level hinder or promote the full enjoyment of rights. A high mortality rate, as indicated by outcome indicators, may grab the attention of stakeholders, but does not indicate where the failure is produced. The indicator sets of ECRI and GlobalChild will have the capacity to direct decisions and activities.

Additionally, due to the interconnectedness and indivisibility of human rights, a rights-based approach requires close intersectoral coordination between stakeholders of health, education, child protection, and other fields. The participatory, transparent and non-discriminatory characteristics that are conferred to the processes when tools such as ECRI (and, in future, GlobalChild) are used in preparing reports, should serve children well. In order to achieve the non-discriminatory realisation of human rights, monitoring tools such as these are critical for facilitating State Parties' accountability and compliance. 


\section{Acknowledgement}

This work was supported by the generous funds from the Canadian Institutes for Health Research and the Michael Smith Foundation for Health Research.

\section{References}

Aikman, S. and Unterhalter, E. (eds.), Practising Gender Equality in Education (Oxfam GB: Oxford, 2007).

Arts, K. and Popovski, V., International Criminal Accountability and the Rights of Children, From Peace to Justice Series (The Hague: Asser Press, 2006).

Ben-Arieh, A., Casas, F., Frønes, I. and Korbin, J., "Multifaceted Concept of Child WellBeing” in A. Ben-Arieh, F. Casas, I. Frønes and J. Korbin (eds.), Handbook of Child Well-Being (Dordrecht: Springer, 2014).

Bentley, K., "A Child-Rights Approach to Monitoring and Indicator Development", HSRC's Child, Youth and Family Development Indicators Project Planning Seminar (Cape Town, South Africa: 17-18 July 2003).

Bequele, A., "Monitoring the Commitment and Child-friendliness of Governments: A New Approach from Africa", Child Abuse \& Neglect 2010 (34(1)), 34-44. DoI: 10.1016/ j.chiabu.2009.08.007.

Bernard Van Leer Foundation, Annual Report 2006 (The Hague, The Netherlands: Bernard van Leer Foundation, 2007).

Bradshaw, J., "Overview: Social Policies and Child Well-Being" in A. Ben-Arieh, F. Casas, I. Frønes and J. Korbin (eds.), Handbook of Child Well-Being (Dordrecht: Springer, 2014).

Bronfenbrenner, U., The Ecology of Human Development: Experiments by Nature and Design (Cambridge, MA: Harvard University Press, 1979).

Carayon, P. et al., "Human Factors Systems Approach to Healthcare Quality and Patient Safety", Applied Ergonomics 2014 (45(1)), 14-25. DOI: 10.1016/j.apergo.2013.04.023.

Carayon, P., Schoofs Hundt, A., Karsh, B., Gurses, A., Alvarado, C., Smith, M. and Flatley Brennan, P., "Work System Design for Patient Safety: The se IPS Model”, BMJ Quality \& Safety 2006 (15), i50-i58. Dor: 10.1136/qshc.2005.015842.

Casas, F., González-Carrasco, M. and Luna, X., "Children's rights and their subjective well-being from a multinational perspective", European Journal of Education 2018 (53), 336-350. Dor: 10.1111/ejed.12294.

CSDH, Commission on Social Determinants of Health, Closing the Gap in a Generation: Health Equity Through Action on the Social Determinants of Health (Geneva: World Health Organisation, 2008). 
Dawes, A., Bray, R. and Van der Merwe, A., Monitoring Child Well-being: A South African Rights-Based Approach (Cape Town: HSCR Press, 2007).

Doek, J. E., “Child Well-Being: Children's Rights Perspective” in A. Ben-Arieh, F. Casas, I. Frønes, and J. Korbin (eds.), Handbook of Child Well-Being (Dordrecht: Springer, 2014).

Donabedian, A., “The Quality of Care: How Can it Be Assessed?", Journal of the American Medical Association, 1988 (26o), 1743-1748. Dor: 10.1001/jama.1988.03410120089033. ECRI, Early Childhood Rights Indicators, Early Childhood Rights Indicators: A Global Monitoring Tool to Implement the United Nations Convention on the Rights of the Child, 2012a.

ECRI, Early Childhood Rights Indicators, Indicadores de los Derechos de la Primera Infancia: Una Herramienta de Monitoreo Global para Omplementar la Convenci ón Sobre los Derechos del Niño de la Organización de las Naciones Unidas, $2012 b$.

FRA, European Union Agency for Fundamental Rights, "Developing Indicators for the Protection, Respect and Promotion of the Right of the Child in the European Union (Conference Edition)", Agency for Fundamental Rights 2010.

Gardener, G, Gardener, A, O'Connell, J., “Using the Donabedian Framework to Examine the Quality and Safety of Nursing Service Innovation", Journal of Clinical Nursing $2013(23(1-2)), 145^{-155}$. DOI: 10.1111/jocn.12146.

Irwin, L. G., Siddiqi, A. and Hertzman, C., "Early Childhood Development: A Powerful Equalizer Final Report", WHO Commission on Social Determinants of Health, \& Human Early Learning Partnership (Vancouver, B.C: HELP, University of British Columbia, 2007).

Lukas, K., Linder, B., Kutrzeba, A. and Sprenger, C., Corporate Accountability: The Role and Impact of Non-judicial Grievance (Northampton, MA: Edward Elgar Publishing Ltd., 2016).

Lundy, L., "United Nations Convention on the Rights of the Child and Child WellBeing” in A. Ben-Arieh, F. Casas, I. Frønes and J. Korbin (eds.), Handbook of Child Well-Being. (Springer: Dordrecht, 2014).

Malhotra, R. and Fasel, N., "Quantitative Human Rights Indicators: A Survey of Major Initiatives" (Turku, Finland: Åbo Akademi University, 2005).

Marope, P. T. M. and Kaga, Y., Investing Against Evidence. The Global State of Early Childhood Care and Education (Paris: UNESCO Publishing, 2015).

Mekonen, Y., "Measuring Government Performance in Realising Child Rights and Child Wellbeing: The Approach and Indicators", Child Indicators Research 2009 (3(2)), 205-241. DOI: 10.1007/s12187-009-9047-5.

Merry, S. E., "Measuring the World: Indicators, Human Rights, and Global Governance", Current Anthropology 2011 (52(3)), S83-S95. DoI: 10.1086/657241. 
Molina, H., Morales, F., Muñoz, R., Hertzman, C., Vaghri, Z. and Bedregal, P., "Piloto de Aplicación en Chile de un Modelo de Evaluación del Cumplimiento de la Convención de Derechos de los Niños en su Comentario General Número 7", Cuadernos Pediatría Social 2012 (18), 37-38.

Newell, P. and Wheeler, J., Rights, Resources and the Politics of Accountability: Claiming Citizenship - Rights, Participation and Accountability (London; New York: Zed Books, 2006).

OHCHR, UN Office of the High Commissioner for Human Rights, The Convention on the Rights of the Child (CRC) (New York and Geneva: United Nations, 1989).

онсHR, UN Office of the High Commissioner for Human Rights \& Save the Children Sweden, The Legislative History of the Convention on the Rights of the Child, Volume 1 (New York and Geneva: United Nations, 2007).

OHCHR, UN Office of the High Commissioner for Human Rights, Human Rights Indicators: A Guide to Measurement and Implementation of Human Rights (New York and Geneva: United Nations, 2012).

OHCHR, UN Office of the High Commissioner for Human Rights, Who Will be Accountable? Human Rights and the Post-2015 Development Agenda (New York and Geneva: OHCHR and the Centre for Economic and Social Rights, 2013).

Op de Beeck, H., "Children's Rights Indicators from Theory to Implementation: The Flemish Case", Child Indicators Research, 2015 (8(2)). DoI: 10.1007/s12187-014-9240-Z Rosga, A. and Satterthwaite, M., "The Trust in Indicators: Measuring Human Rights", Berkeley Journal of International Law 2009 (27(2)). DoI: 10.15779/Z38Go7R.

Sandin, B., "History of Children's Well-Being" in A. Ben-Arieh, F. Casas, I. Frønes and J. Korbin (eds.), Handbook of Child Well-Being (Dordrecht: Springer, 2014).

UNCRC, United Nations Committee on the Rights of the Child, "General Comment No. 7: Implementing Child Rights in Early Childhood", Convention on the Rights of the Child (New York and Geneva: United Nations, 2006a).

UNCRC, United Nations Committee on the Rights of the Child, UNICEF, and the Bernard van Leer Foundation (eds.), A Guide to General Comment 7: Implementing Child Rights in Early Childhood (The Hague: Bernard van Leer Foundation, 2006b).

UNCRC, United Nations Committee on the Rights of the Child, "General Comment No. 13: The Right of the Child to Freedom from All Forms of Violence", Convention on the Rights of the Child (New York and Geneva: United Nations, 2011).

UnICEF United Nations Children's Fund, "Measuring and Monitoring Child Protection Systems: Proposed Core Indicators for the East Asia and Pacific Region", Strengthening Child Protection Systems (New York and Geneva: United Nations, 2012).

UNICEF, "Manual for the measurement of juvenile justice indicators", United Nations Office of Drug and Crime (New York and Geneva: United Nations, 2006). 
Vaghri, Z. and Erdemli, I., "A Desk Top Review of the Existing Indicators on Articles and General Comments of the United Nations Convention on the Rights of the Child," Zeitschrift für Menschenrechte, Journal for Human Rights 2019 (13(1)), 94-117.

Vaghri, Z. and Gibson, G., "Exploring the Impact of a CRC Monitoring Survey on Child Rights and ECD Stakeholders: A Qualitative Research Study," manuscript in progress. Vaghri, Z., Arkadas, A., Hertzman, C., Krappmann, L., Gertsch, L., Cabral, M., Ulkuer, N. and Kikuchi-White, A., "Manual for Early Childhood Rights Indicators (Manual of the Indicators of General Comment 7): A Guide for State Parties Reporting to the Committee on the Rights of the Child. Draft 3.o", (New York and Geneva: UNICEF, 2010).

Vaghri, Z., Krappmann, L., Arkadas, A., Hertzman, C. and Fenn, C., Piloting the Indicators of General Comment $\left(\mathrm{GC}_{7}\right)$ : Implementing Child Rights in Early Childhood. Final Report submitted to UNICEF (Tanzania) and the government of the United Republic of Tanzania. (2011).

Vaghri, Z., Krappmann, L., Arkadas, A., Hertzman, C., Fenn, C. and Diaz, C. (2013), Piloting the Indicators of General Comment $\left(\mathrm{GC}_{7}\right)$ : Implementing Child Rights in Early Childhood. Final Report submitted to UNICEF (Chile) and the Government of Chile (2013).

Vaghri, Z., Arkadas, A., Kruse, S. and Hertzman, C., "CRC General Comment 7 Indicators Framework: A Tool for Monitoring the Implementation of Child Rights in Early Childhood", Journal of Human Rights 2012 (10(2)), 178-188. DoI: 10.1080/14754835.2011.568916.

Vandenbogaerde, A., "Towards Shared Accountability in International Human Rights Law" in Law and Cosmopolitan Values Series Volume 7 (Cambridge, UK: Intersentia, 2016). 


\title{
Appendix I: List of the indicators of the Early Childhood Rights Indicators (E C RI)
}

\author{
Early Childhood Rights Indicators 8 :
}

Cluster 1: General Measures of Implementation

Indicator 1: Dissemination of $\mathrm{GC}_{7}$ :

Indicator 2: A Positive Agenda

Indicator 3: Human Rights Training

Indicator 4: Data Collection Systems

Cluster 2: Definition of the Child

Indicator 5: Early Child Development

Cluster 3: Civil Rights and Freedoms

Indicator 6: Birth Registration

Cluster 4: Family Environment and Alternative Care

Indicator 7: Participation in Family Decision-Making Indicator 8: Violence against Young Children

\section{Cluster 5: Basic Health and Welfare}

Indicator 9: Basic Material Needs

Indicator 10: Breastfeeding and Complementary Feeding

Indicator 11: Access to and Use of Health Services

Indicator 12: Age-appropriate Health Education

\section{Cluster 6: Education, Leisure and Cultural Activities}

Indicator 13: Provision of Early Childhood Education and Care Services

Indicator 14: Educational Provision for Vulnerable Young Children

8 At the time of the pilot in Tanzania (2009-2010), the $\mathrm{GC}_{7}$ indicators were comprised of fifteen indicator sets. During the digitization of the indicators and the development of the ECRI tool, a new indicator set was added (Indicator 5: Early Childhood Development). Additionally, Indicator 10, which was comprised of 10a and 10b, was separated into two stand-alone indicators of Indicator 10 and Indicator 11. This brought the total number of indicators to 17, as ECRI stands today. 
Indicator 15: Knowledge of Rights and Capacity to Support their Realization Indicator 16: Play, Leisure and Rest Opportunities for Young Children

\section{Cluster 7: Special protection measures}

Indicator 17: Inclusive Policy and Provisions for Marginalized Groups 


\section{Appendix II: Excerpt from Indicator 16 of the Early Childhood Rights Indicators (E CRI)}

\section{Indicator Set 16: Play, Leisure and Rest Opportunities for Young Children}

\section{Related to Structure}

\section{Question 1}

Are there legal provisions or policy commitments that address opportunities for play and leisure time for all young children with particular attention to gender, disability and those children in need of special protection measures?
( ) No
$\biguplus$ Partially
OYes
OUnknown
Not Applicable

\section{Suggestions:}

- Promote policies that ensure opportunities for play and leisure time for young children. For example, see: "Ready, Steady, Play! A National Play Policy" in Ireland: http://www. dcya.gov.ie/viewdoc. asp?fn=/documents/Publications/NCOPlayPolicy eng.pdf. 


\section{Related to Process}

\section{Question 5}

Are there initiatives in place to inform parents/caregivers and professionals about the developmental benefits of play?

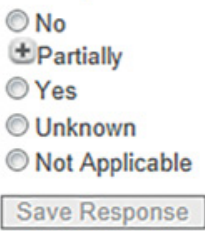

\section{Question 6}

Do city and regional planning consultation processes facilitate the participation of parents and children?
No
†Partially
Yes
Unknown
Not Applicable
Save Response

\section{Related to Outcome}

\section{Question 9}

Has there been an increase in quality and quantity of safe physical spaces for recreation, sports and play?
No
$\biguplus$ Partially
Yes
Unknown
Not Applicable
Save Response 